Article

\title{
Extracting Travelers' Preferences toward Electric Vehicles Using the Theory of Planned Behavior in Lahore, Pakistan
}

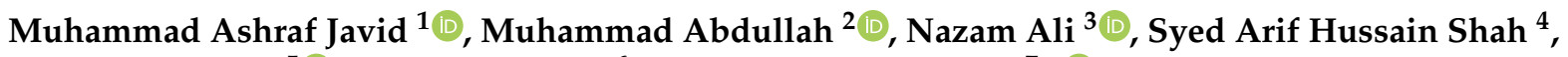 \\ Panuwat Joyklad ${ }^{5}{ }^{\circ}$, Qudeer Hussain ${ }^{6}$ and Krisada Chaiyasarn $7, *(\mathbb{B}$
}

1 Department of Civil Engineering, NFC Institute of Engineering and Fertiliser Research, Faisalabad 38090, Pakistan; ma.javid@iefr.edu.pk

2 Department of Civil Engineering, National University of Computer \& Emerging Sciences, Lahore 54770, Pakistan; abdullah.rana@nu.edu.pk

3 Department of Civil Engineering, University of Management and Technology, Lahore 54770, Pakistan; nazam.ali@umt.edu.pk

4 Department of City and Regional Planning, University of Engineering and Technology, Lahore 39161, Pakistan; syedarifhussain@uet.edu.pk

5 Department of Civil and Environmental Engineering, Faculty of Engineering, Srinakharinwirot University, Nakhonnayok 26120, Thailand; panuwatj@g.swu.ac.th

6 Center of Excellence in Earthquake Engineering and Vibration, Department of Civil Engineering, Chulalongkorn University, Bangkok 45142, Thailand; ebbadat@hotmail.com

7 Thammasat Research Unit in Infrastructure Inspection and Monitoring, Repair and Strengthening (IIMRS), Thammasat School of Engineering, Faculty of Engineering, Thammasat University Rangsit, Rangsit 12121, Thailand

Citation: Javid, M.A.; Abdullah, M.; Ali, N.; Shah, S.A.H.; Joyklad, P.;

Hussain, Q.; Chaiyasarn, K.

Extracting Travelers' Preferences toward Electric Vehicles Using the Theory of Planned Behavior in Lahore, Pakistan. Sustainability 2022, 14, 1909. https://doi.org/10.3390/ su14031909

Academic Editors: Victor Manuel Ferreira Moutinho and António Carrizo Moreira

Received: 31 December 2021

Accepted: 4 February 2022

Published: 8 February 2022

Publisher's Note: MDPI stays neutral with regard to jurisdictional claims in published maps and institutional affiliations.

Copyright: (C) 2022 by the authors. Licensee MDPI, Basel, Switzerland. This article is an open access article distributed under the terms and conditions of the Creative Commons Attribution (CC BY) license (https:// creativecommons.org/licenses/by/ $4.0 /)$.
* Correspondence: ckrisada@engr.tu.ac.th

\begin{abstract}
The high use of gasoline and diesel vehicles results in environmental pollution and loss of natural resources. The use of electric vehicles can be socially beneficial and reduce air pollution. In this research study, the main aims are to identify the potential of Electric Vehicles (EVs) in Pakistan using a Stated Preferences (SP) survey. An SP questionnaire was designed using the theoretical framework of the Theory of Planned Behavior (TPB). This questionnaire consisted of travelers' personal and travel characteristics and various statements designed to address the variables of TPB such as Attitudes Towards the Electric Vehicles, Subjective Norms (SN), Perceived Behavioral Control (PBC), and Behavioral Intentions (BI). The behavior items were designed in the context of travelers' willingness to buy and use EVs. Confirmatory Factor Analyses (CFAs) were conducted to validate the designed hypotheses related to the variables of TPB. The cross-analysis revealed that there are variations in responses across different occupations, trip distances, travel modes, and vehicle ownership. The developed structural models showed that the Attitudes and PBC have a positive influence on BI and PBC, which also have a direct impact on travelers' willingness to use EV. The SN, PBC, and Attitudes are significant predictors of behavioral intentions in the willingness to buy EV and PBC is not a direct predictor of travelers' willingness to buy an EV. The BI acts as a mediator to explain the indirect effects of Attitudes, SN, and PBC on willingness to purchase and use an EV. In the end, a framework is also proposed for the behavior-related interventions to promote the EVs considering the socio-economic context of Pakistan.
\end{abstract}

Keywords: electric vehicle; stated preferences; travel behavior; TPB; SEM; Lahore

\section{Introduction}

Ambient air quality has been deteriorating around the world, particularly in developing countries. The transportation sector is among the major sources of greenhouse gas emissions and particulate matter causing air pollution [1-3]. Conventional vehicles contribute to global warming and are not sustainable modes of transportation. The increasing number of vehicles gives rise to congestion, which is associated with high emission levels 
of particulate matter [4,5]. Air pollution, in general, and the pollution caused by traffic congestion, in particular, poses significant health risks and a further increase in traffic may aggravate the situation [6]. Emissions caused by conventional vehicles increase personal exposure to various kinds of air pollutants. Those exposed to high levels of traffic pollution, such as traffic wardens and shopkeepers near major roads, may experience respiratory symptoms [7]. Similarly, air pollution is also linked with cardiovascular dysfunctions, childhood asthma, and cancer [8,9].

The reduction in the volume of conventional vehicles can reduce air pollution and save several lives per year [10]. This could be achieved by the introduction of sustainable mobility alternatives such as Electric Vehicles (EVs). The increasing environmental pollution has compelled government authorities and policymakers to promote and incentivize EVs [11] These vehicles generally use electric motors for propulsion and are seen as a potential solution for mitigating traffic-related environmental problems. A study indicated that EVs with a $100 \%$ penetration rate and renewable energy sources may reduce 330 premature deaths per year in the Greater Toronto and Hamilton area [12]. A numerical simulation study performed along a highway in Italy found that replacing only about $50 \%$ of the conventional vehicles with EVs may bring about a significant reduction in air pollution [13]. However, the environmental benefits such as reduction in greenhouse gas emissions and human exposure due to EVs depend on several factors including the type of electric vehicle, energy source, driving and charging patterns, availability of charging stations, government policies, and climate [14-16].

Like other developing countries, the rising number of conventional private vehicles has degraded the environmental quality in Pakistan. Moreover, outdoor air pollution has been found to exceed the standard limits in the major cities causing 22,000 premature adult deaths in Pakistan $[17,18]$. The introduction of EVs in Pakistan may improve the air quality and reduce fuel dependency; however, there are certain barriers to the adoption of EVs resulting in their low share in the current traffic situation. Furthermore, there is a dearth of literature on modeling the intentions to buy and use EVs in Pakistan. It is important to understand the consumer's purchase and usage intentions to propose appropriate policy recommendations.

Several studies have attempted to explore and model the people's intentions to buy and use EVs [19-21]. Theory of Planned Behavior (TPB) is one of the theoretical frameworks which has been applied to predict the adoption of EVs [22]. Consumer adoption of an innovation can be predicted by the behavioral responses which, in turn, can be directly predicted by intentions. According to the TPB framework, intentions can be predicted by Attitudes towards behavior, Subjective Norms (SN), and Perceived Behavioral Control (PBC) [23]. An existing study found the determinants of TPB theory, particularly, attitudes, to be significant predictors of intentions to purchase EVs [24]. Extended versions of the TPB have also been employed to model consumers' purchase intentions. For example, factors such as product perception, cognitive status, and incentive policies coupled with benefits can alter the attitude and PBC to be significant in extracting the intentions to purchase EVs [25].

There is a lack of literature on the intentions to buy and use EVs in Pakistan. Keeping in view the emerging market and potential of EVs, this study aims at modeling the people's intentions to buy and use EVs in Lahore, Pakistan using the theory of planned behavior. The data was collected using a questionnaire-based survey. Structural equation modeling was then used to verify the model specification of the theory of planned behavior. A theoretical framework is also presented to promote the EVs.

The rest of the article is divided into the following sections. Section 2 includes an overview of the literature relevant to EVs. Section 3 presents the research methods. Section 4 discusses the descriptive statistics; the findings of CFA and SEM. Section 5 discusses some of the policy interventions. Finally, the conclusions, limitations, and recommendations are presented in last Section 6. 


\section{Literature Review}

Conventional vehicles consume oil-based fuels and cause air pollution, which results in several negative consequences including global warming and health-related risks. For example, ambient air pollution is linked with various diseases including respiratory problems, cardiovascular diseases, and cancer, etc. [26,27]. In addition, conventional vehicles use non-renewable energy sources increasing carbon footprint. These negative consequences have urged government authorities, policymakers, and consumers to evaluate alternative sustainable mobility options such as electric vehicles (EVs). EVs comprise vehicles containing various technologies such as battery electric vehicles (BEVs), hybrid electric vehicles (HEVs), extended-range battery electric vehicles (E-REVs), and plug-in hybrid electric vehicles (PHEVs). EVs may provide several advantages such as reduced fuel consumption, less air pollution and reduction in carbon footprint, etc. However, certain barriers are restricting the widespread adoption of EVs including battery technology, costs, charging infrastructure, lack of incentive programs, sustainability of fuel source, and deceptive car dealerships, etc. [28-30]. Furthermore, various psychological barriers affect the intention to adopt EVs [31]. The determinants of intentions to purchase and use EVs need to be identified to make appropriate policy decisions.

Consumers' intentions to buy and use EVs can be modeled using various theoretical frameworks such as Theory of Planned Behavior (TPB), Norm Activation Model (NAM), Diffusion of Innovation (DOI) Theory and, Protection Motivation Theory, etc. [22,32]. Theory of planned behavior has been used for various purposes in the transportation sector such as modeling the intentions to reduce pollution caused by traffic [33], modeling the intentions to adopt eco-friendly transport modes [34,35], and modeling the intentions to use public transport, etc. [36-38]. According to the TPB, attitudes, $\mathrm{PBC}$, and $\mathrm{SN}$ can predict the intentions to adopt an innovation $[23,39,40]$. Therefore, the TPB as well as its extensions, which may include several predictors of intentions together with attitudes, PBC and SN, can be used to model the intentions to purchase and use EVs. Several studies have utilized the TPB and found it to be appropriate in predicting the intentions to adopt EVs [41-43].

A study conducted in Norway attempted to explain the role of the TPB constructs and demographic variables on BEV purchase intentions through multiple hierarchical regression analysis [21]. The results showed that $\mathrm{SN}, \mathrm{PBC}$, and environmental-economic attributes were positively related to $\mathrm{BEV}$ purchase intentions with $\mathrm{PBC}$ being the strongest predictor. A study carried out in India found that moral norms and environmental concerns besides attitude, SN, and PBC have a positive relationship with the intentions of the buyers to adopt EVs [43]. The SN was found to be the most significant determinant of the intentions followed by PBC. Researchers extended the TPB to include policy mix characteristics along with psychological factors as predictors of buyers' intentions [42]. The psychological factors including attitude, Personal Norm (PN), SN, and PBC were found to have positive effects on the intentions to buy EVs. Among some of the policies, pertinent characteristics, coherence, and credibility had positive effects on the intentions to purchase EVs. [24] also extended the TPB to include personal moral norms along with the three primary constructs. Personal moral norms were included because environmental concerns are associated with pro-environmental behavior. For instance, environmental concern has been found to play a role in the purchase of HEVs [32,44]. Hamzah and Tanwir (2021) integrated the TPB and NAM to model the green purchase intention of HEVs in the suburban areas of Greater Kuala Lumpur, Malaysia. Perceived green value, $\mathrm{PBC}$, and $\mathrm{SN}$ were found to have a positive relation to the green purchase intention of HEVs [45]. A study result with the extension of TPB indicated that emotions and attitudes were the strongest predictors of the intentions to use EVs followed by SN in a Belgian sample [34]. The existing evidence suggests that TPB is an appropriate approach to model the intentions to purchase and use EVs.

The existing literature indicates that the TPB is a useful approach to model the intentions to buy and use EVs. However, there is a lack of such studies in the context of Lahore, Pakistan. Therefore, this study fills this gap by modeling the intentions to buy and use EVs using the TPB in the context of the Lahore city. Based on literature review, it was hy- 
pothesized that the travelers' attitudes towards EVs ownership and use, social norms, and perceived behavior control regarding the ownership and use of EV have a direct influence on behavioral intentions (BI), where indirect influence on ownership and use of EV through $\mathrm{BI}$ variable plays a role of mediator. It was also hypothesized that perceived difficulty in the ownership and use of EV may have a direct influence on travelers' willingness to use and buy. This study also tries to assess the possible difference among the different segments of the travelers in the context of their attitudes, intentions, norms, behavioral control, and willingness to use and buy the EV.

\section{Research Methods}

\subsection{Study Area}

Lahore city is one of the largest city of Pakistan with an estimated population of 11 million [46] and was chosen for this case study. This city is highly populated and hosts many educational, recreational, and medical facilities. It is abutted by many industrial areas creating a lot of employment opportunities for the residents and the people who live in the sub-urban settings of Lahore city. These aspects of Lahore city generate a lot of travel demand on road infrastructure. Private ownership and its usage are also increasing at an alarming rate [47]. The share of public transportation modes in the modal share is quite less for Lahore city [48]. The increase in urban population and traffic demand results in problems of traffic congestion and urban degradation in terms of polluting the environment and increasing the social costs. The consumption of gasoline and diesel oils in transportation causes air pollution. It is the need of the time to search for the potential of EVs in the Lahore city for the betterment of the environment.

However, it is not an easy process to shift from fuel operated vehicles to EVs. Certain obstacles such as market prices, technical malignancy, state financial subsidies, and social drawbacks could undermine the penetration rate of EVs in the current market [49]). Varying terrain also poses a threat to the penetration of EVs in Pakistan [50]. The country also faced an energy shortage problem, which was soon overcome through the development of power plants. This fast track development led to excessive electricity production which can expedite the penetration of EVs [51]. Nonetheless, the government is committed to introduce EVs at a large scale and thus, slashed sale tax on EVs besides other incentives in the recent auto development policy [52].

\subsection{Survey Instrument}

A stated preferences questionnaire was designed using the theoretical background of the TPB. The first part of the questionnaire consisted of socio-economic demographics (SEDs) of the respondents. The selected SEDs included gender, marital status, age, education, income, profession, vehicle ownership, travel mode and its trip frequency, trip distance, and travel cost of the daily one-way trip. The second part of the questionnaire comprised the carefully designed statements based on the variables of the TPB. Four statements were designed for the attitudes towards the EVs. These statements determine the travelers liking or preference attitudes to use and buy EVs considering the low registration taxes, availability of charging stations, government subsidies on purchasing EV, and environmental concerns. The variable of PBC consisted of three statements that identify the difficulties in buying and using EVs. The difficulty scenarios included government registration and taxation system, the problem of charging stations on longer trips, and service quality of existing road infrastructure. Three statements were constructed concerning to SN variable. These statements identify the respondent's potential to use and buy an EV under some social influence and benefits. The subjective influence and benefits scenarios included when EV use becomes popular in the society, and when someone sees his/her friends and family members using an EV. The variable of behavioral intentions consisted of three statements that determine the travelers' intentions to use an EV. The intentions were asked considering the availability of charging stations, charging time, and travel cost with an EV. Travelers' willingness to use and buy an EV was also asked. Three statements 
intended to get responses on willingness to use and four statements were intended to get perceptions related to willingness to buy an EV. The willingness to use an EV was inquired in the context of air pollution reduction, preservation of natural resources, and presence of cheap electricity. The items targeting the responses for willingness to purchase an EV included four different scenarios: cheaper fuel costs than diesel/gasoline vehicles, lower maintenance costs and battery price compared to gasoline/diesel vehicles, accurate information on mileage and longer battery lives. All the items in part 2 of the questionnaire were evaluated using a five-point Likert scale i.e., strongly disagree (1), disagree (2), neutral (3), agree (4), and strongly agree (5) [53]. This scale was adopted for the reliability of the obtained data. It is easy and understandable for the respondents and is, therefore, suitable for extracting exact information.

\subsection{Surveying and Sampling Methods}

The people residing in Lahore were targeted as the respondents for this stated preference study. They comprised the current vehicle users and non-vehicle users (potential users) who may own an EV in the future. The respondents using different transport modes and belonging to various economic groups were surveyed and included in the target sample. The survey locations were selected based on a convenience-based sampling strategy. The target respondents, however, were selected randomly at each chosen location. The chosen locations contained few commercial places, educational institutions (government as well as private), and official establishments where it was convenient to approach the target respondents. For this study, the sample size was decided keeping in view the requirements of Structural Equation Modeling (SEM). It is recommended that a minimum sample size of 200 is required to minimize the bias in the results $[54,55]$. Other recommendations included a ratio of 10 observations per indicator [56] and the minimum sample size should be at least ten times the number of free parameters in the structural model $[57,58]$. Considering these recommendations, it was hypothesized that a sample size of around 400 samples would be sufficient to reduce bias in the results and obtain a reliable structural model. This survey was carried out by university students who were properly trained about the items in the questionnaire and the adopted survey method. The students interviewed all the respondents. The survey was conducted using paper-and-pencil approach. All the necessary efforts were made to ensure the collection of a reliable dataset. A sample of 402 respondents was collected.

\subsection{Data Analysis Methods}

CFA and SEM were performed on the collected data. The SEM is a multivariate statistical technique employed to observe the correlations between latent variables [59]. These are the variables which are not directly observable but can be indirectly observed through their effects on other observable variables. In the context of the theory of planned behavior, attitudes, SN, PBC, and BI are all examples of latent variables. Initially, CFA was conducted to verify the association of different observed and latent variables in accordance with the background of TPB [60]. The CFA was carried out using Maximum Likelihood (ML) approach and Equamax rotation. The ML method is among the most commonly used methods when the researchers need to run CFA [61]. The values of Cronbach's alpha were also calculated to check if there is any consistency between the responses of the respondents. Cronbach's values of $>0.7$ and $>0.5$ show acceptable and moderate level of reliability, respectively [62,63]. A structural model is a combination of measurement models. The SEM model is used to extract the correlations between observed and latent variables. These models are combined to construct the structure and identify the significant structural equations between the factors under study. The credibility of the structural model is checked by comparing the values of the goodness of fit indices with their permissible values in the literature. In this study, the following statistical parameters were used to check the model reliability i.e., comparative fit index (CFI), the ratio of chi-square to the degree of freedom (CMIN/DF), adjusted goodness of fit index (AGFI), the goodness of fit 
index (GFI), root mean square residual (RMR) and root mean square error of approximation (RMSEA). It is recommended that the value of CMIN/DF should be between 2-5, and CFI, GFI, and AGFI should be greater than 0.9, and RMR and RMSEA need to be less than $0.08[54,55,64]$. All the analysis was conducted on SPSS and AMOS software.

\section{Analysis and Discussion}

\subsection{Descriptive Analysis of the Sample}

The descriptive analysis on the data indicated higher representation of male and single respondents (Table 1). The underrepresentation of the females can be justified by the fact that their working population is quite small. The percentage of young respondents was high (i.e., approx. 65\% of the respondents below 30 years of age). It is explained by the fact that the Lahore's population mainly consists of younger population and thus, this age distribution seems to be consistent with the population [65]. Students and employees made up most of the responses. A majority of the respondents belongs to the low-income group due to the considerable proportion of students in the sample. About $45.27 \%$ of respondents declared that they own one or more than one vehicle. The modal share of private vehicles, motorcycles, and public transport is $33.83 \%, 28.61 \%$, and $12.94 \%$, respectively. An overwhelming majority of the respondents $(>70 \%)$ reported a trip frequency of five to six days a week or higher.

Table 1. SEDs of the respondents.

\begin{tabular}{|c|c|}
\hline Variable & Distribution (\%) \\
\hline Gender & $\begin{array}{l}\text { Male (85.57), } \\
\text { female (14.43) }\end{array}$ \\
\hline Marital status & $\begin{array}{l}\text { Single (66.92), } \\
\text { married }(33.08)\end{array}$ \\
\hline Age (years) & $\begin{array}{c}\text { under } 20(30.85), \\
21-30(35.82), \\
31-40(16.17), \\
41-50(11.19) \\
\text { more than } 50(5.98)\end{array}$ \\
\hline Education & $\begin{array}{c}\text { High school or below (21.39), } \\
\text { F.Sc./F.A. (16.17), } \\
\text { diploma (8.96), } \\
\text { bachelor (38.31), } \\
\text { master or higher (15.17) }\end{array}$ \\
\hline Profession & $\begin{array}{c}\text { Students }(38.31), \\
\text { civil employees }(8.96), \\
\text { private employees }(19.40), \\
\text { business }(12.94), \\
\text { others }(20.41)\end{array}$ \\
\hline Income & $\begin{array}{c}\text { Below 20,000 (43.78), } \\
\text { 21,000-30,000 (10.21), } \\
\text { 31,000-40,000 (8.21), } \\
41,000-60,000(11.69) \\
\text { 61,000-80,000 (8.21), } \\
\text { more than 81,000 (17.91) }\end{array}$ \\
\hline Vehicle ownership & $\begin{array}{c}\text { None (54.73), } \\
1(35.57), \\
2(7.46), \\
\text { more than } 2(2.24)\end{array}$ \\
\hline
\end{tabular}


Table 1. Cont.

\begin{tabular}{|c|c|}
\hline Variable & Distribution (\%) \\
\hline Vehicle driving license & $\begin{array}{l}\text { Yes (37.31), } \\
\text { No (62.69) }\end{array}$ \\
\hline Usual travel mode & $\begin{array}{c}\text { Walk/bicycle (9.95), } \\
\text { private car (33.83), } \\
\text { motorcycle (28.61), } \\
\text { auto-rickshaw / taxi (8.46), } \\
\text { campus/office transport (6.22), } \\
\text { public transport (12.94) }\end{array}$ \\
\hline Trip frequency & $\begin{array}{c}\text { Almost every day a week (57.96), } \\
\text { 5-6 days a week (16.67), } \\
\text { 3-4 days a week (15.17), } \\
\text { 1-2 days a week (4.73), } \\
\text { a few times a month (5.47) }\end{array}$ \\
\hline Trip length $(\mathrm{km})$ & $\begin{array}{l}<10 \mathrm{~km}(62.43) \\
>10 \mathrm{~km}(37.56)\end{array}$ \\
\hline
\end{tabular}

\subsection{Confirmatory Factor Analysis}

Two CFA were performed on collected responses. The first analysis was done on three explanatory variables of TPB i.e., attitudes towards EC (attitudes), Subjective Norms (SN), and Perceived Behavioral Control (PBC) (Table 2). This CFA confirms the design hypothesis of questionnaire statements and the association between latent and observed variables. The value of the Kaiser-Meyer-Olkin measure of sampling adequacy is more than 0.7 which shows that the collected sample size is adequate to run factor analysis [66]. Cronbach's alpha values were estimated for all three factors. The computed alpha values are greater than 0.7 predicting a satisfactory level of reliability of the latent factors and the internal consistency among the respondents. The loading values shown in Table 2 represent the variance explained by a particular observed variable on the underlying factors. The results of the attitudes factor show that the factor loadings values are more than 0.7 and respondents' attitudes are high to use an EV considering the availability of charging stations, low registration and other taxes and government-subsidized policies, and environmental value of EV. Travelers have a high belief in recognition of the environmental value of EV which can help to promote the ownership and use it. The results of the PBC variable show that most of the respondents have a mutual agreement on the perceived difficulty in owning and using an EV due to government taxation policies, availability of charging stations on longer trips, and compatibility of existing roads service quality with the requirements of EVs. The SN variable shows that the popularity of EVs in the society greatly affects people's choices to use EVs. Also, the awareness and influence through family members, friends, and colleagues would play a significant role in promoting the use of sustainable vehicle technologies in society.

Second CFA was carried out on the questionnaire items regarding the respondents' Behavioral Intentions (BI), Willingness to Use an EV (WUEV), and Willingness to Buy an EV (WBEV). The value of the Kaiser-Meyer-Olkin measure of sampling adequacy is more than 0.7 which shows that the collected sample size is adequate to run factor analysis. Cronbach's alpha values for all three factors were found to be satisfactory (i.e., >0.7) (Table 3). The variable of $\mathrm{BI}$ shows that the travelers possess high intentions to use an EV considering its use is cheaper than gasoline and diesel vehicles, availability of charging stations, and efficient charging points. Most respondents are willing to use EVs for reduction in air pollution, preservation of natural resources, and on the provision of cheap electricity. The results of the WBEV variable show that the respondents possess a high willingness to buy an EV given sufficient awareness about the mileage of EVs, longer battery lives, and low initial and maintenance costs compared to conventional oil/diesel vehicles, and. The factor 
analysis results predicted positive norms, attitudes, and intentions of the respondents towards purchasing and using EVs.

Table 2. Rotated factor loadings of attitudes, PBC and SN variables.

\begin{tabular}{|c|c|c|c|c|}
\hline \multirow{2}{*}{ Observed Variables } & \multirow{2}{*}{ Mean } & \multicolumn{3}{|c|}{ Factor } \\
\hline & & Attitudes & PBC & SN \\
\hline $\begin{array}{l}\text { I like to use an electric vehicle if charging stations are } \\
\text { available easily. (Attitudes-1) }\end{array}$ & 4.059 & 0.847 & & \\
\hline $\begin{array}{l}\text { I prefer to own an electric vehicle if registration and other } \\
\text { taxes are low. (Attitudes-2) }\end{array}$ & 4.084 & 0.838 & & \\
\hline $\begin{array}{l}\text { I like to use an EV if the government provides subsidies on } \\
\text { it. (Attitudes-3) }\end{array}$ & 4.000 & 0.794 & & \\
\hline $\begin{array}{l}\text { I prefer to use an electric vehicle as it is more } \\
\text { environmentally friendly. (Attitudes- } 4 \text { ) }\end{array}$ & 4.194 & 0.733 & & \\
\hline $\begin{array}{l}\text { The government tax and registration system may make it } \\
\text { difficult to own and use an electric vehicle. (PBC-1) }\end{array}$ & 3.604 & & 0.782 & \\
\hline $\begin{array}{l}\text { I believe that the quality of existing roads would be a } \\
\text { problem in the promotion of an electric vehicle. (PBC-2) }\end{array}$ & 3.694 & & 0.745 & \\
\hline $\begin{array}{l}\text { Traveling on longer trips with an electric vehicle would be } \\
\text { difficult because of charging station unavailability. (PBC-3) }\end{array}$ & 3.826 & & 0.618 & \\
\hline $\begin{array}{l}\text { I would only move to EV when it will become popular in } \\
\text { society. (SN-1) }\end{array}$ & 3.559 & & & 0.786 \\
\hline $\begin{array}{l}\text { I would only move to an electric vehicle when I see my } \\
\text { friends/colleagues using it. (SN-2) }\end{array}$ & 3.107 & & & 0.692 \\
\hline $\begin{array}{l}\text { I would only move to an electric vehicle when I see my } \\
\text { family members using it. (SN-3) }\end{array}$ & 3.407 & & & 0.614 \\
\hline$\%$ of variance explained & & 26.728 & 19.917 & 14.808 \\
\hline Cronbach's Alpha & & 0.852 & 0.780 & 0.712 \\
\hline \multicolumn{5}{|l|}{ KMO and Bartlett's Test } \\
\hline \multicolumn{3}{|c|}{ Kaiser-Meyer-Olkin Measure of Sampling Adequacy } & \multicolumn{2}{|c|}{0.813} \\
\hline \multirow{3}{*}{ Bartlett's Test of Sphericity } & \multicolumn{2}{|c|}{$\begin{array}{l}\text { Approximate } \\
\text { Chi-Square }\end{array}$} & \multicolumn{2}{|c|}{1404.075} \\
\hline & \multicolumn{2}{|c|}{$\begin{array}{c}\text { Degree of } \\
\text { freedom (DF) }\end{array}$} & \multicolumn{2}{|c|}{55} \\
\hline & \multicolumn{2}{|c|}{ Significance } & \multicolumn{2}{|c|}{0.000} \\
\hline
\end{tabular}

Table 3. Rotated factor loadings of behavioral intentions, willingness to buy and use EV.

\begin{tabular}{|c|c|c|c|c|}
\hline \multirow[b]{2}{*}{ Observed Variables } & \multirow[b]{2}{*}{ Mean } & \multicolumn{3}{|c|}{ Factors } \\
\hline & & $\begin{array}{l}\text { Willingness } \\
\text { to Use EV } \\
\text { (WUEV) }\end{array}$ & $\begin{array}{l}\text { Behavioral } \\
\text { Intentions } \\
\text { (BI) }\end{array}$ & $\begin{array}{c}\text { Willingness } \\
\text { to Buy EV } \\
\text { (WBEV) }\end{array}$ \\
\hline $\begin{array}{l}\text { I am willing to use EV for the preservation of natural } \\
\text { resources. (WUEV-1) }\end{array}$ & 3.880 & 0.887 & & \\
\hline $\begin{array}{l}\text { I am willing to use EV to reduce air pollution in the } \\
\text { city. (WUEV-2) }\end{array}$ & 3.972 & 0.856 & & \\
\hline $\begin{array}{l}\text { I am willing to use EV considering the availability of } \\
\text { cheap electricity. (WUEV -3) }\end{array}$ & 4.037 & 0.690 & & \\
\hline
\end{tabular}


Table 3. Cont.

\begin{tabular}{|c|c|c|c|c|}
\hline \multirow[b]{2}{*}{ Observed Variables } & \multirow[b]{2}{*}{ Mean } & \multicolumn{3}{|c|}{ Factors } \\
\hline & & $\begin{array}{l}\text { Willingness } \\
\text { to Use EV } \\
\text { (WUEV) }\end{array}$ & $\begin{array}{l}\text { Behavioral } \\
\text { Intentions } \\
\text { (BI) }\end{array}$ & $\begin{array}{l}\text { Willingness } \\
\text { to Buy EV } \\
\text { (WBEV) }\end{array}$ \\
\hline $\begin{array}{l}\text { I would prefer to use EV when it is cheaper than a } \\
\text { gasoline/diesel vehicle. (BI-1) }\end{array}$ & 3.982 & & 0.835 & \\
\hline $\begin{array}{l}\text { I believe that my intention to buy EV depends on the } \\
\text { availability of charging stations. (BI-2) }\end{array}$ & 4.102 & & 0.753 & \\
\hline $\begin{array}{l}\text { The charging time will affect my intentions to use an } \\
\text { electric vehicle. (BI-3) }\end{array}$ & 4.124 & & 0.613 & \\
\hline $\begin{array}{l}\text { I would buy EV if I have more information about the } \\
\text { mileage with one-time charging. (WBEV-1) }\end{array}$ & 4.082 & & & 0.821 \\
\hline $\begin{array}{l}\text { I would buy EV if the initial purchase cost is less than } \\
\text { petrol or diesel vehicles. (WBEC-2) }\end{array}$ & 4.164 & & & 0.718 \\
\hline $\begin{array}{l}\text { I would like to buy EV if the maintenance and battery } \\
\text { costs are less than petrol or diesel vehicles. (WBEC-3) }\end{array}$ & 4.206 & & & 0.704 \\
\hline $\begin{array}{l}\text { I would like to buy EV if the charging batteries have a } \\
\text { long life. (WBEC-4) }\end{array}$ & 4.278 & & & 0.563 \\
\hline$\%$ of variance explained & & 22.374 & 22.041 & 20.980 \\
\hline Cronbach's Alpha & & 0.786 & 0.713 & 0.702 \\
\hline \multicolumn{5}{|c|}{ KMO and Bartlett's Test } \\
\hline \multicolumn{4}{|c|}{ Kaiser-Meyer-Olkin Measure of Sampling Adequacy } & 0.828 \\
\hline \multirow{3}{*}{ Bartlett's Test of Sphericity } & & \multicolumn{2}{|c|}{ Approximate Chi-Square } & 1404.623 \\
\hline & & \multicolumn{2}{|c|}{ Degree of freedom (DF) } & 45 \\
\hline & & \multicolumn{2}{|c|}{ Significance } & 0.000 \\
\hline
\end{tabular}

\subsection{Categorical Analysis of Travelers' Perceptions}

A cross-analysis of some personal and travel characteristics with responses on attitudes, BI, SN, PBC, and willingness to use and buy an EV was done. Average scores were estimated, and comparisons were drawn among different groups using radar diagrams. Figure 1a shows that there is a difference in perceptions between respondents who own a vehicle and those who do not own a vehicle. The differences in perceptions between respondents with a vehicle and without a vehicle are more for attitudes, and BI. The difference in average responses is less for variables of SN and PBC. The respondents with no vehicle have a low willingness to use and buy an EV. The category of others in Figure $1 \mathrm{~b}$ included entrepreneurs/business and workers-oriented travelers who did not fall in the employees' category. Figure $1 \mathrm{~b}$ shows that the civil and private employees have more behavioral intentions and willingness to buy EV than other respondents' categories. The level of willingness to use of employees and students is the same. The employees also possess better attitudes towards EV and their beliefs on the perceived difficulty in owning and using an EV are also higher than students and other respondents. There is not much difference among the three categories for beliefs on the $\mathrm{SN}$ variable.

Figure 1c shows the cross-distribution for the travelers' frequent travel mode. The present users of private vehicles have better attitudes, intentions, and willingness to use and buy an EV than public transport users. The motorcycle and public transport users have felt less perceived difficulty and social influence in the ownership and use of EVs. These results imply that the private vehicle users could be potential groups to promote the ownership and use of EVs. Figure 1d also shows the differences in stated perceptions of traveler's trip distance. The travelers whose trip distance is more than $10 \mathrm{~km}$ have more willingness, intentions, and positive attitudes towards the EC. 


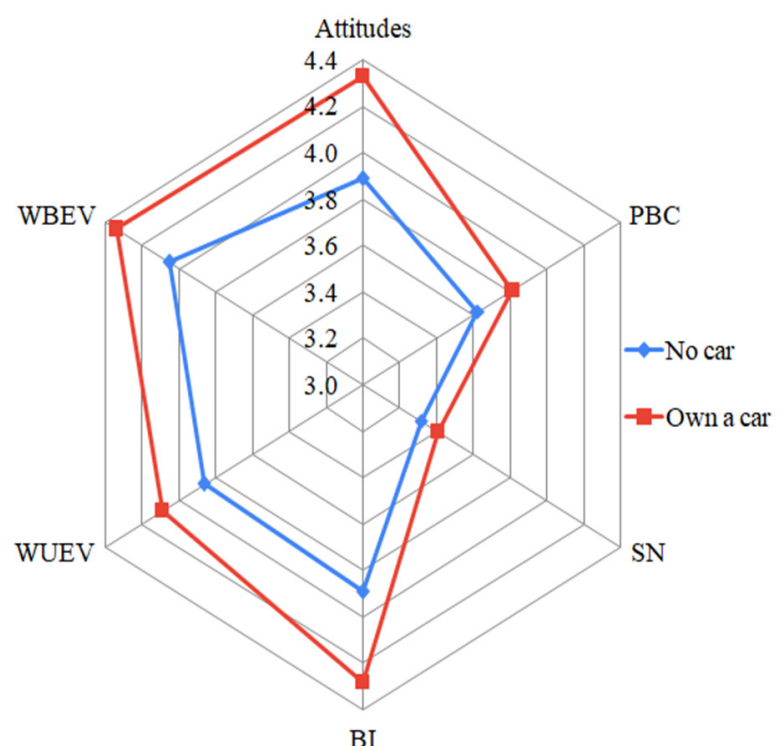

(a)

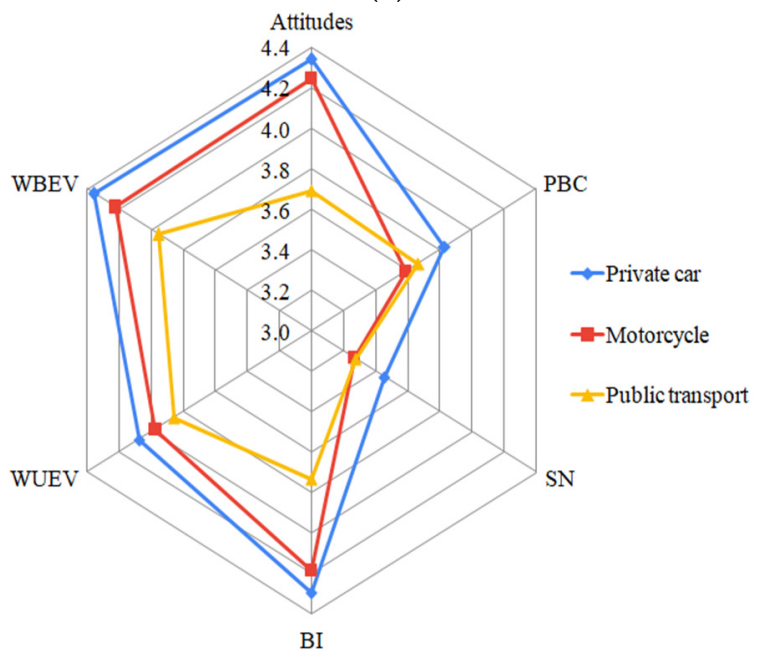

(c)

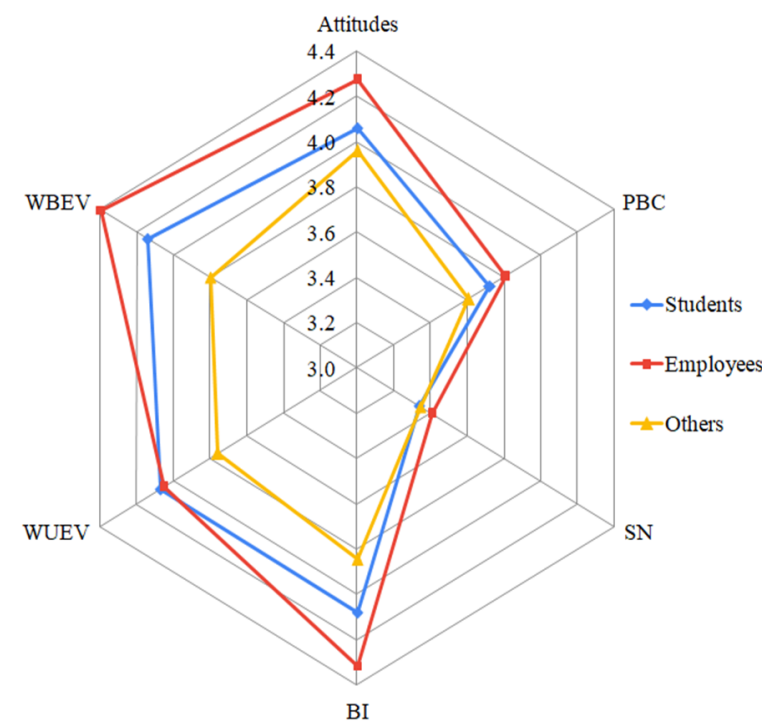

(b)

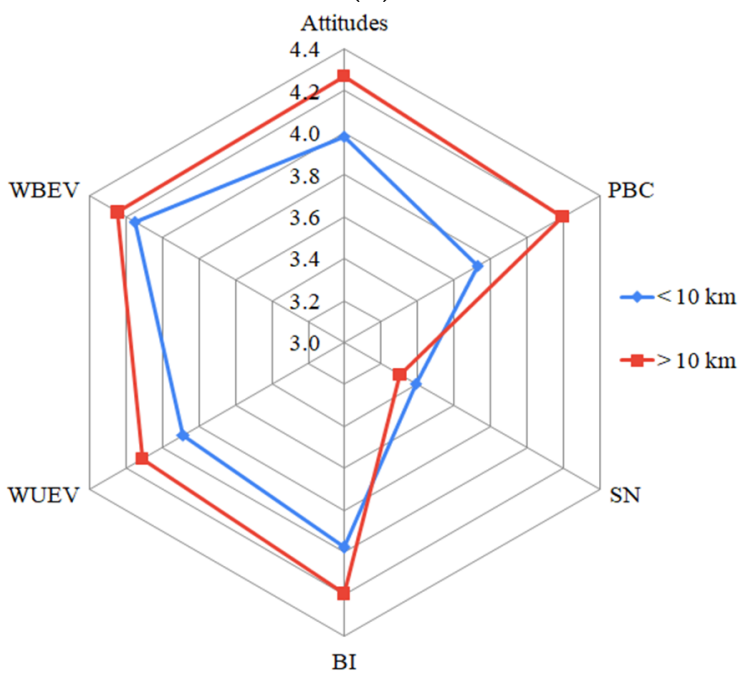

(d)

Figure 1. Distribution of average responses across different segments of the travelers. (a) Distribution for vehicle ownership. (b) Distribution for occupation. (c) Distribution for travel mode. (d) Distribution for travel distance.

\subsection{Structural Equation Modeling (SEM)}

Two structural models were made using results of the factor analyses considering the theoretical specification of the TPB. The first structural model was developed of travelers' willingness to use EV as shown in Figure 2. This structural model shows that there is a positive association between variables of attitudes, SN, and PBC. All three correlations were significant at a $1 \%$ level of significance. The structural coefficient between variables of attitudes and BI is positive and significant at a $1 \%$ level of significance. Similar results were reported by [24]. This positive estimate shows that the travelers who have positive attitudes towards EV also have high behavioral intentions. Other studies have also shown that attitudes are significant predictors of customers' behavioral intentions [24,25]. The structural equation between SN and BI variables was insignificant. However, previous studies have shown that the $\mathrm{SN}$ variable is a significant predictor of intentions towards EVs [21]. The structural relationships between PBC and BI variables are significant and positive which depicts that despite perceived difficulties in owning and using an EV, still, the travelers have positive intentions to consider the use of EV. This strong predictive 
behavior of PBC with intentions is the same as reported in other studies [21,25,43]. The attitudes, $\mathrm{SN}$, and PBC variables explain about $81 \%$ of the variance in BI. In addition, the $\mathrm{PBC}$ also has a direct and significant structural relationship with travelers' willingness to use the EVs. This structural coefficient is significant at a $10 \%$ level of significance. It shows that the respondents have shown willingness to use EV despite perceived difficulties in ownership and usage. Both BI and PBC explain around 35\% of the variance in travelers' willingness to use an EV. The BI acts as a mediator to explain the indirect influence of PBC and attitudes on the willingness to use. The values of CMIN/DF fall between 2 to 5, values of GFI and CFI are greater than 0.9, and values of RMSEA and RMR are below 0.08 . The value of AGFI is also near 0.9. The comparison of the threshold values of the indices shows that the developed model is adequate to predict the behavior of the respondents and framework has good reliability in order to explain the willingness of the travelers to use an EV under the influence of PBC, attitudes, and BI.

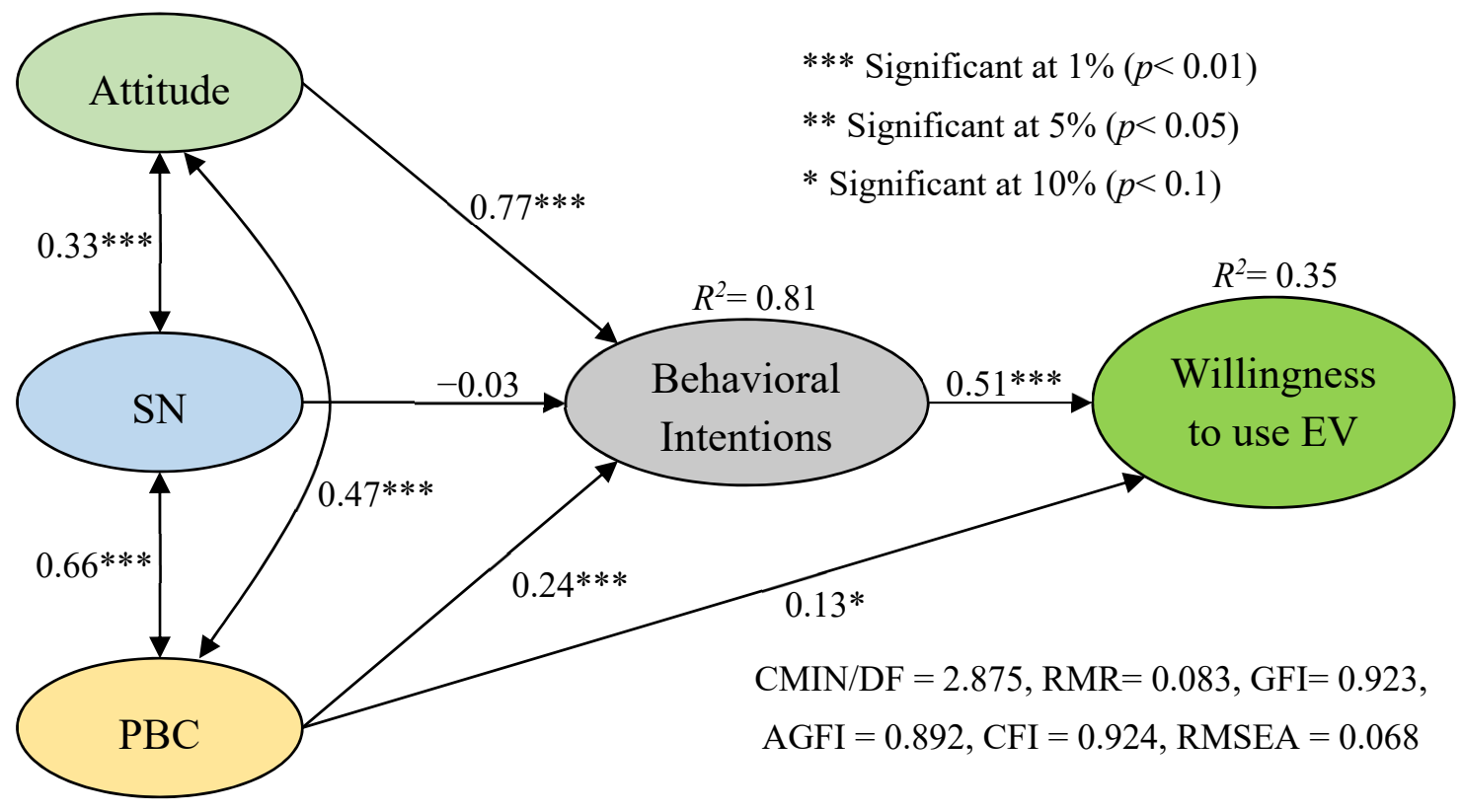

Figure 2. Developed SEM for use of EV.

The second structural model was constructed for travelers' willingness to buy EV as shown in Figure 3. The results of this model show that the nature and significance of attitudes and $\mathrm{PBC}$ with $\mathrm{BI}$ are the same as discussed earlier. The structural relationship between SN and BI is significant at a 10\% level of significance. The negative coefficient between SN and BI shows that there are travelers who have positive intentions to consider EVs but possess low social or subjective beliefs in defining their norms towards the EV. The attitudes, $\mathrm{SN}$ and $\mathrm{PBC}$ explain almost $79 \%$ of the variance in BI. The structural equation of the $\mathrm{PBC}$ variable with the willingness to buy EV is insignificant. The BI explains almost $65 \%$ of the variance in travelers' willingness to buy EVs. The values of the indices are within the permissible range which shows that this SEM has potential to extract the willingness of travelers to buy EV. 


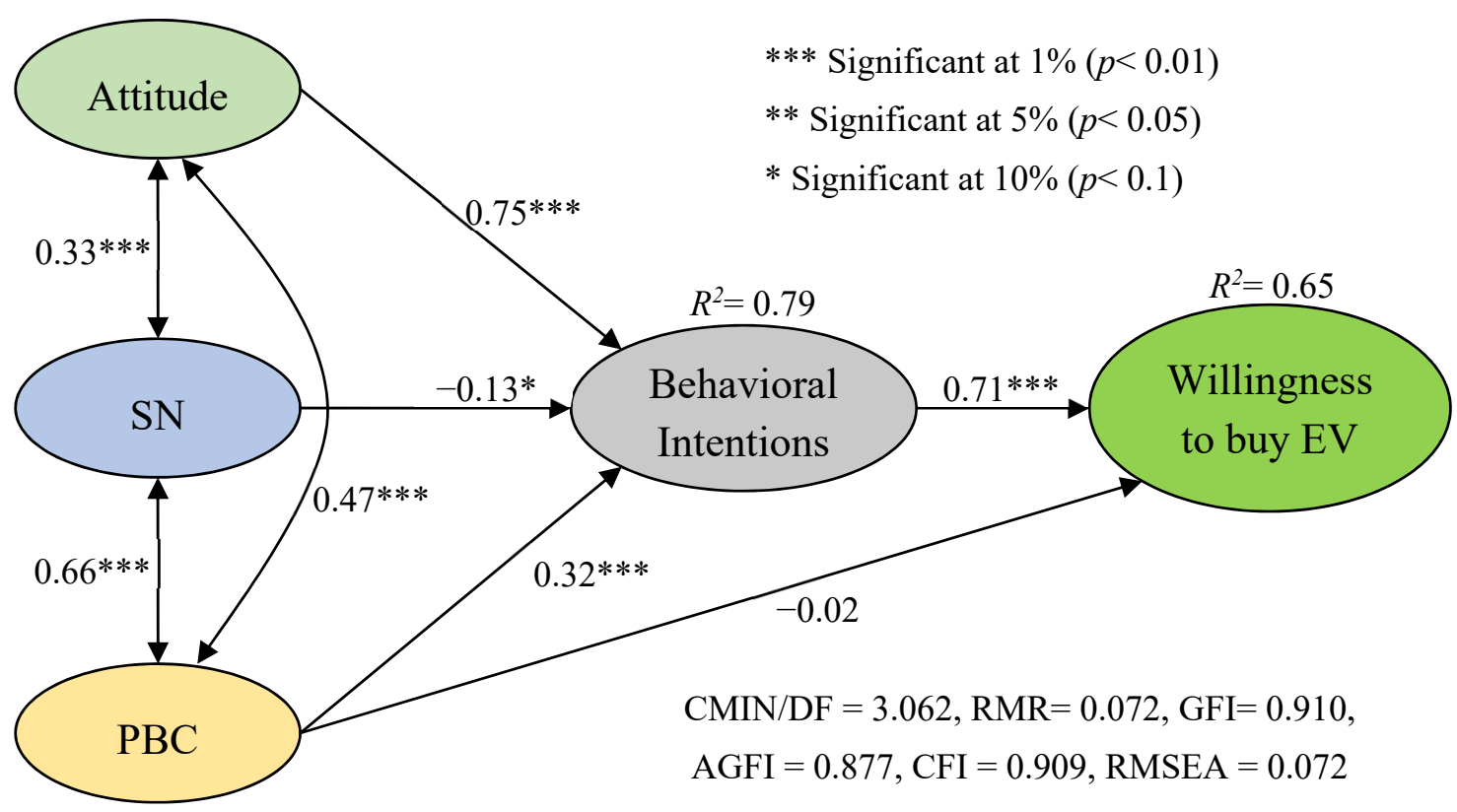

Figure 3. Developed SEM for willingness to buy EV.

\section{Policy Implications}

This section discusses the policy implications of the survey and analysis results. The travelers possess positive attitudes towards EV ownership and use. The attitudes are strong predictors of intentions and also have indirect effects on travelers' willingness to use and own an EV. The availability of charging stations, low ownership, registration taxes, government subsidies, and cheap electricity are great motives to develop supporting attitudes among travelers. Therefore, the financial incentive policy measures can have potential impacts on the adoption behavior of consumers towards EVs. In addition, the information and number of charging stations could have a positive impact on the decision making process of consumers. However, the information on the number of charging stations is currently lacking in the country. If consumers have more information about the charging infrastructure, they would be more willing to adopt to EVs. At present, it is not difficult to assess that insufficient charging infrastructure is one of the main barriers in the adoption of EVs in Pakistan. Convenient charging places in the country could lead to more likelihood of adoption EVs. The easy availability of charging points, cheap electricity and incentive programs would also help to improve attitudes and change behavioral intentions. The importance of monetary costs is linked with the ownership. Regardless of the personal incomes, consumers are more intended to adopt for travel options which are less costly (Gardner and Abraham, 2007). Therefore, the discounts of taxation and government subsidies could potentially accelerate the use and adoption of EVs as it is evident from US-based EV trials (Caperello and Kurani, in press), which implies that cost minimization is one of the factors for the adoption of EVs. The easiness of the ownership process and subsidies on taxes can be handy to reduce the level of perceived difficulty [14-16]. The development of these attitudes would help in promoting the ownership and usage of environmentally-friendly travel alternatives $[14,15]$. The travelers' have positive intentions towards EV despite high beliefs on the perceived difficulty in the ownership and use. Other studies have also emphasized incentive programs in terms of charging infrastructure development and economic incentives to the potential owners of EVs [25,28-30]. The awareness about negative outcomes of gasoline/diesel vehicles such as air pollution and positive benefits of EVs such as an environmentally friendly vehicle can prove to be strong policy interventions [32,44,45]. A pro-environmental behavior can potentially have vital impact on the adoption of EVs. EVs have quite a number of noteworthy benefits which can be attributed to their low carbon emissions and extended mileage range. Different 
vendors/car dealers can use this as an advertising strategy to attract and inspire more local customers to adopt EVs owing to their environmental benefits. Right now, the prices of EVs are around $30 \%$ more than conventional gasoline vehicles in Pakistan. The manufacturers of EVs should offer lower prices in order to attract more customers. For the sake of avoiding excessive prices, manufacturing companies should offer variety of affordable EV designs. It shows that the pro-environmental behavior of customers towards EVs has moderating effects on their behavioral intentions to adopt EVs. Such soft policy interventions can be useful in improving the ownership and usage of environmental-friendly travel modes $[36,67]$. Results also showed that private vehicle users, employees, present vehicle owners, and travelers with longer trip distances have more positive attitudes, behavioral control, intentions, and willingness to own and use EV than other mentioned groups. Finally, a conceptual framework of behavioral intervention strategies has been proposed in Figure 4 to promote ownership and usage of EVs. Figure 4 shows that it is required to identify the target groups for effective behavioral policies. The potential target groups could be current vehicle users and employees. The next stage of the proposed framework includes some behavioral intervention policies required to develop favorable attitudes, reduction in perceived difficulty, and social influence or pressure to enhance behavioral intentions. This framework further highlights that once the change happens in the behavioral intention, it would help in encouraging the EV purchase and usage.

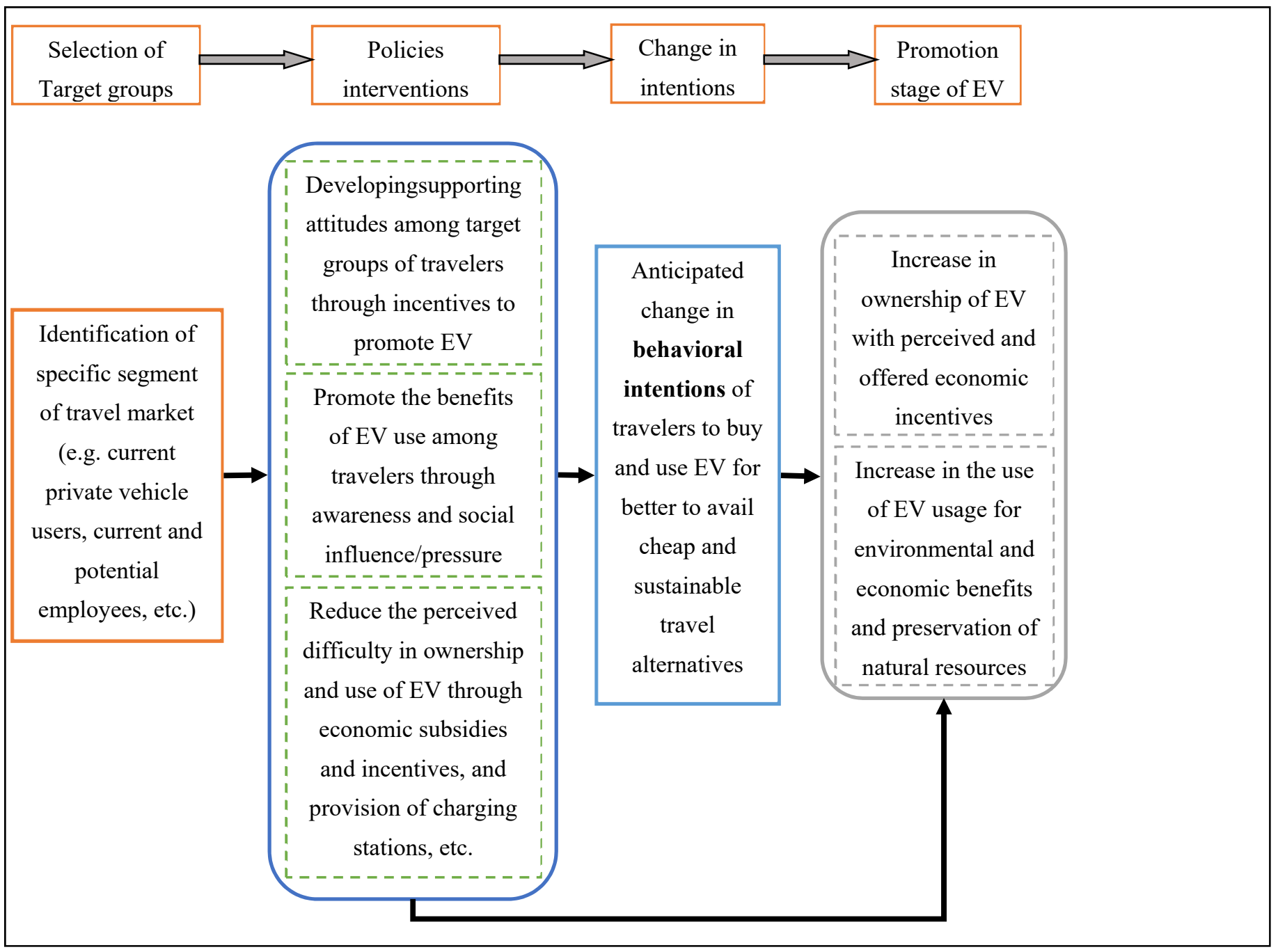

Figure 4. A proposed framework for the promotion of EVs. 


\section{Conclusions}

This study identified the potential of electric vehicles in Lahore, Pakistan using the results of a stated preference questionnaire survey. This questionnaire survey was designed under the framework of TPB. The survey results revealed that the target groups of travelers have high preferences to own and use EVs. The results of CFA confirmed the association of observed variables with their corresponding latent variables or factors as per the conceptual framework of the TPB. The confirmed factors have good reliability in predicting the travelers' behavioral intentions and willingness to own and use an EV. The cross-examination revealed that there are differences across different segments of the travel market in their attitudes, perceived behavioral control, intentions, and willingness to use and buy an EV. The employees, present vehicle owners, and users of private vehicles have more willingness to use and buy an EV. The attitudes and PBC are significant direct predictors of behavioral intentions, and PBC is also a direct predictor of travelers' willingness to use an EV. The variable of behavioral intention is a direct predictor of travelers' willingness to use and buy an EV and also plays a significant role as a mediator to explain the influence of attitudes, $\mathrm{SN}$, and PBC on willingness to use or buy an EV. In the structural model of willingness to buy, the $\mathrm{SN}$ has a significant and negative correlation with behavioral intentions.

Based on the survey and analysis results, this study proposed a conceptual framework to promote the ownership and use of EVs in Pakistan and other developing regions with similar socio-economic fabric of the society. The identification of target segments of the travel market is important to achieve the required objectives. The development of positive attitudes among travelers, social influence, and reducing perceived difficulties in the ownership and use of EV would help in developing positive intentions and promote the ownership and use. The economic benefits, government subsidies on ownership taxes, and availability of charging stations can play important role in easing difficulties in ownership and usage. Also, awareness among travelers regarding associated environmental benefits would be handy in developing positive attitudes and intentions. For this purpose, awareness campaigns and programs are needed to be initiated. The findings of this study are based on the results of a stated preferences survey. Such survey results usually suffer from bias as the actual preferences of the travelers may be different from the stated. Nonetheless, Pakistan has a relatively younger population who is generally more aware of the new technologies and therefore, the results are valid for this target population. Because this research study focused on the intentions of customers towards adoption of EVs instead of actual adoption. Therefore, it is imperative to conduct a follow-up survey study to identify and investigate these respondents' actual adoption behavior towards EVs. In a subsequent study, it can be explored how particular segment of respondents respond to specific type and brand of EV. These research results are only examined qualitatively, further qualitative analysis is required to study the impacts of specific policy measures for their validation. Another limitation was the under-representation of older respondents in the sample. Despite limitations, the results and findings of this study provide useful knowledge about the policies needed to be considered for the promotion of EVs in a developing country like Pakistan.

Author Contributions: Conceptualization, M.A.J. and N.A.; Methodology, M.A.J.; Software, M.A.J.; Validation, M.A.J., N.A. and M.A.; Formal Analysis, M.A.J.; Investigation, M.A.J.; Resources, N.A., P.J., Q.H.; Data Curation, S.A.H.S.; Writing—original draft preparation, M.A.J.; Writing—review and editing, K.C.; Visualization, Q.H.; Supervision, N.A; Project administration, N.A.; Funding acquisition, N.A. All authors have read and agreed to the published version of the manuscript.

Funding: This research received no external funding.

Institutional Review Board Statement: This is a non-intervention study and did not collect any personal identifying details. The research was conducted in accordance with the guidelines issued by the University of Management and Technology, Lahore.

Informed Consent Statement: Not applicable. 
Data Availability Statement: Data can be made available from corresponding author upon reasonable request.

Acknowledgments: This work was supported by the Thammasat Research Unit in Infrastructure Inspection and Monitoring, Repair and Strengthening (IIMRS), Thammasat School of Engineering, Faculty of Engineering, Thammasat University Rangsit, Klong Luang Pathumthani, Thailand. Authors also extend their appreciation to the respondents for their time and efforts to make this study possible.

Conflicts of Interest: The authors declare no conflict of interest.

$\begin{array}{ll}\text { Abbreviations } \\ \text { EV } & \text { Electric vehicle } \\ \text { TPB } & \text { Theory of Planned Behavior } \\ \text { SEM } & \text { Structural Equation Modeling } \\ \text { CFA } & \text { Confirmatory Factor Analysis } \\ \text { BI } & \text { Behavioral Intention } \\ \text { PBC } & \text { Perceived Behavioral Control } \\ \text { SN } & \text { Social Norms } \\ \text { WUEV } & \text { Willingness to Use an EV } \\ \text { WBEV } & \text { Willingness to Buy an EV } \\ \text { SEDs } & \text { Socio-Economic Demographics }\end{array}$

\section{References}

1. Jahangir, S.; Ahmad, S.S.; Aziz, N.; Shah, M.T.A. Spatial Variation of Nitrogen dioxide Concentration in Private and Public Hospitals of Rawalpindi and Islamabad, Pakistan. J. Int. Environ. Appl. Sci. 2013, 8, 16-24.

2. Shabbir, Y.; Khokhar, M.F.; Shaiganfar, R.; Wagner, T. Spatial variance and assessment of nitrogen dioxide pollution in major cities of Pakistan along N5-Highway. J. Environ. Sci. 2016, 43, 4-14. [CrossRef] [PubMed]

3. Guttikunda, S.K.; Lodoysamba, S.; Bulgansaikhan, B.; Dashdondog, B. Particulate pollution in Ulaanbaatar, Mongolia. Air Qual. Atmos. Health 2013, 6, 589-601. [CrossRef]

4. Colbeck, I.; Nasir, Z.A.; Ahmad, S.; Ali, Z. Exposure to PM10, PM2.5, PM1 and Carbon Monoxide on Roads in Lahore, Pakistan. Aerosol Air Qual. Res. 2011, 11, 689-695. [CrossRef]

5. Ali, Z.; Rauf, A.; Sidra, S.; Nasir, Z.A.; Colbeck, I. Air Quality (Particulate Matter) at Heavy Traffic Sites in Lahore, Pakistan. J. Anim. Plant Sci. 2015, 25, 644-648.

6. Zhang, K.; Batterman, S. Air pollution and health risks due to vehicle traffic. Sci. Total Environ. 2013, 450-451, 307-316. [CrossRef] [PubMed]

7. Kamal, A.; Qamar, K.; Gulfraz, M.; Anwar, M.A.; Malik, R.N. PAH exposure and oxidative stress indicators of human cohorts exposed to traffic pollution in Lahore city (Pakistan). Chemosphere 2015, 120, 59-67. [CrossRef]

8. Gasana, J.; Dillikar, D.; Mendy, A.; Forno, E.; Ramos Vieira, E. Motor vehicle air pollution and asthma in children: A meta-analysis. Environ. Res. 2012, 117, 36-45. [CrossRef] [PubMed]

9. Ghorani-Azam, A.; Riahi-Zanjani, B.; Balali-Mood, M. Effects of air pollution on human health and practical measures for prevention in Iran. J. Res. Med. Sci. 2016, 21, 65.

10. Leirião, L.F.L.; Debone, D.; Pauliquevis, T.; do Rosário, N.M.É.; Miraglia, S.G.E.K. Environmental and public health effects of vehicle emissions in a large metropolis: Case study of a truck driver strike in Sao Paulo, Brazil. Atmos. Pollut. Res. 2020, 11, 24-31. [CrossRef]

11. Langbroek, J.H.M.; Franklin, J.P.; Susilo, Y.O. The effect of policy incentives on electric vehicle adoption. Energy Policy 2016, 94, 94-103. [CrossRef]

12. Gai, Y.; Minet, L.; Posen, I.D.; Smargiassi, A.; Tétreault, L.-F.; Hatzopoulou, M. Health and climate benefits of Electric Vehicle Deployment in the Greater Toronto and Hamilton Area. Environ. Pollut. 2020, 265, 114983. [CrossRef] [PubMed]

13. Ferrero, E.; Alessandrini, S.; Balanzino, A. Impact of the electric vehicles on the air pollution from a highway. Appl. Energy 2016, 169, 450-459. [CrossRef]

14. Nanaki, E.A.; Koroneos, C.J. Comparative economic and environmental analysis of conventional, hybrid and electric vehiclesThe case study of Greece. J. Clean. Prod. 2013, 53, 261-266. [CrossRef]

15. Buekers, J.; Van Holderbeke, M.; Bierkens, J.; Panis, L.I. Health and environmental benefits related to electric vehicle introduction in EU countries. Transp. Res. Part D Transp. Environ. 2014, 33, 26-38. [CrossRef]

16. Requia, W.J.; Mohamed, M.; Higgins, C.D.; Arain, A.; Ferguson, M. How clean are electric vehicles? Evidence-based review of the effects of electric mobility on air pollutants, greenhouse gas emissions and human health. Atmos. Environ. 2018, 185, 64-77. [CrossRef]

17. Zafar Ilyas, S. A Review of Transport and Urban Air Pollution in Pakistan. J. Appl. Sci. Environ. Manag. 2007, 11, 113-121. 
18. Anjum, M.S.; Ali, S.M.; Imad-ud-din, M.; Subhani, M.A.; Anwar, M.N.; Nizami, A.S.; Ashraf, U.; Khokhar, M.F. An Emerged Challenge of Air Pollution and Ever-Increasing Particulate Matter in Pakistan; A Critical Review. J. Hazard. Mater. 2021, 402, 123943. [CrossRef] [PubMed]

19. Mohamed, M.; Higgins, C.; Ferguson, M.; Kanaroglou, P. Identifying and characterizing potential electric vehicle adopters in Canada: A two-stage modelling approach. Transp. Policy 2016, 52, 100-112. [CrossRef]

20. Lin, B.; Wu, W. Why people want to buy electric vehicle: An empirical study in first-tier cities of China. Energy Policy 2018, 112, 233-241. [CrossRef]

21. Simsekoglu, Ö.; Nayum, A. Predictors of intention to buy a battery electric vehicle among conventional car drivers. Transp. Res. Part F Traffic Psychol. Behav. 2019, 60, 1-10. [CrossRef]

22. Rezvani, Z.; Jansson, J.; Bodin, J. Advances in consumer electric vehicle adoption research: A review and research agenda. Transp. Res. Part D Transp. Environ. 2015, 34, 122-136. [CrossRef]

23. Ajzen, I. The theory of planned behavior. Organ. Behav. Hum. Decis. Process. 1991, 50, 179-211. [CrossRef]

24. Wang, S.; Fan, J.; Zhao, D.; Yang, S.; Fu, Y. Predicting consumers' intention to adopt hybrid electric vehicles: Using an extended version of the theory of planned behavior model. Transportation. 2016, 43, 123-143. [CrossRef]

25. Huang, X.; Ge, J. Electric vehicle development in Beijing: An analysis of consumer purchase intention. J. Clean. Prod. 2019, 216, 361-372. [CrossRef]

26. Raaschou-Nielsen, O.; Andersen, Z.J.; Hvidberg, M.; Jensen, S.S.; Ketzel, M.; Sørensen, M.; Hansen, J.; Loft, S.; Overvad, K.; Tjønneland, A. Air pollution from traffic and cancer incidence: A Danish cohort study. Environ. Heal. A Glob. Access Sci. Source 2011, 10, 67. [CrossRef]

27. Mannucci, P.M.; Harari, S.; Martinelli, I.; Franchini, M. Effects on health of air pollution: A narrative review. Intern. Emerg. Med. 2015, 10, 657-662. [CrossRef] [PubMed]

28. Egbue, O.; Long, S. Barriers to widespread adoption of electric vehicles: An analysis of consumer attitudes and perceptions. Energy Policy 2012, 48, 717-729. [CrossRef]

29. Vassileva, I.; Campillo, J. Adoption barriers for electric vehicles: Experiences from early adopters in Sweden. Energy 2017, 120, 632-641. [CrossRef]

30. Zarazua de Rubens, G.; Noel, L.; Sovacool, B.K. Dismissive and deceptive car dealerships create barriers to electric vehicle adoption at the point of sale. Nat. Energy 2018, 3, 501-507. [CrossRef]

31. Franke, T.; Neumann, I.; Bühler, F.; Cocron, P.; Krems, J.F. Experiencing Range in an Electric Vehicle: Understanding Psychological Barriers. Appl. Psychol. 2012, 61, 368-391. [CrossRef]

32. Bockarjova, M.; Steg, L. Can Protection Motivation Theory predict pro-environmental behavior? Explaining the adoption of electric vehicles in the Netherlands. Glob. Environ. Chang. 2014, 28, 276-288. [CrossRef]

33. Ru, X.; Qin, H.; Wang, S. Young people's behaviour intentions towards reducing PM2.5 in China: Extending the theory of planned behaviour. Resour. Conserv. Recycl. 2019, 141, 99-108. [CrossRef]

34. Moons, I.; de Pelsmacker, P. Emotions as determinants of electric car usage intention. J. Mark. Manag. 2012, 28, 195-237. [CrossRef]

35. Moons, I.; De Pelsmacker, P. An Extended Decomposed Theory of Planned Behaviour to Predict the Usage Intention of the Electric Car: A Multi-Group Comparison. Sustainability 2015, 7, 6212-6245. [CrossRef]

36. Javid, M.A.; Okamura, T.; Nakamura, F.; Tanaka, S.; Wang, R. Factors Influencing the Acceptability of Travel Demand Management Measures in Lahore: Application of Behavioral Theories. Asian Transp. Stud. 2015, 3, 447-466. [CrossRef]

37. Heath, Y.; Gifford, R. Extending the theory of planned behavior: Predicting the use of public transportation. J. Appl. Soc. Psychol. 2002, 32, 2154-2189. [CrossRef]

38. Chen, C.F.; Chao, W.H. Habitual or reasoned? Using the theory of planned behavior, technology acceptance model, and habit to examine switching intentions toward public transit. Transp. Res. Part F Traffic Psychol. Behav. 2011, 14, 128-137. [CrossRef]

39. Ajzen, I. From Intentions to Actions: A Theory of Planned Behavior. In Action Control; Kuhl, J., Beckmann, J., Eds.; Springer: Berlin/Heidelberg, Germany, 1985; pp. 11-39. [CrossRef]

40. Fishbein, M.; Ajzen, I. Belief, Attitude, Intention, and Behavior: An Introduction to Theory and Research; Addison-Wesley: Boston, MA, USA, 1975.

41. Haustein, S.; Jensen, A.F. Factors of electric vehicle adoption: A comparison of conventional and electric car users based on an extended theory of planned behavior. Int. J. Sustain. Transp. 2018, 12, 484-496. [CrossRef]

42. Li, L.; Wang, Z.; Wang, Q. Do policy mix characteristics matter for electric vehicle adoption? A survey-based exploration. Transp. Res. Part D Transp. Environ. 2020, 87, 102488. [CrossRef]

43. Shalender, K.; Sharma, N. Using extended theory of planned behaviour (TPB) to predict adoption intention of electric vehicles in India. Environ. Dev. Sustain. 2021, 23, 665-681. [CrossRef]

44. Heffner, R.R.; Kurani, K.S.; Turrentine, T.S. Symbolism in California's early market for hybrid electric vehicles. Transp. Res. Part D Transp. Environ. 2007, 12, 396-413. [CrossRef]

45. Hamzah, M.I.; Tanwir, N.S. Do pro-environmental factors lead to purchase intention of hybrid vehicles? The moderating effects of environmental knowledge. J. Clean. Prod. 2021, 279, 123643. [CrossRef]

46. Punjab Bureau of Statistics Punjab Development Statistics. Available online: http://www.bos.gop.pk/developmentstat (accessed on 30 June 2020). 
47. Batool, Z.; Carsten, O.; Jopson, A. Road safety issues in Pakistan: A case study of Lahore. Transp. Plan. Technol. 2012, 35, 31-48. [CrossRef]

48. Aziz, A.; Nawaz, M.S.; Nadeem, M.; Afzal, L. Examining suitability of the integrated public transport system: A case study of Lahore. Transp. Res. Part A Policy Pract. 2018, 117, 13-25. [CrossRef]

49. Asghar, R.; Rehman, F.; Ullah, Z.; Qamar, A.; Ullah, K.; Iqbal, K.; Aman, A.; Nawaz, A.A. Electric vehicles and key adaptation challenges and prospects in Pakistan: A comprehensive review. J. Clean. Prod. 2021, 278, 123375. [CrossRef]

50. Ul-Haq, A.; Jalal, M.; Hassan, M.S.; Sindi, H.F.; Shah, A.; Anjum, A. Electric transportation in pakistan under CPEC project: Technical framework and policy implications. IEEE Access 2020, 8, 162394-162420. [CrossRef]

51. Iqbal, A.; Nadeem, A.; Arslan, M.M.; Javed, M.A.; Arshad, N. Does Pakistan have enough electricity generation to support massive penetration of electric vehicles? In Proceedings of the 2021 IEEE Texas Power and Energy Conference, TPEC 2021, College Station, TX, USA, 4-5 February 2021; pp. 1-6.

52. The News. Dissecting Govt's New Auto Policy 2021-26. Available online: https://www.thenews.com.pk/print/921238 -dissecting-govt-s-new-auto-policy-2021-26 (accessed on 25 January 2022).

53. Vagias, Wade M. Likert-Type Scale Response Anchors. Clemson International Institute for Tourism \& Research Development, Department of Parks, Recreation and Tourism Management. Clemson University. 2006. Available online: http://media.clemson edu/cbshs/prtm/research/resources-for-research-page-2/Vagias-Likert-Type-Scale-Response-Anchors.pdf (accessed on 30 June 2020).

54. Boomsma, A.; Hoogland, J.J. The Robustness of LISREL Modeling Revisited. In Structural Equation Models: Present and Future. A Festschrift in Honor of Karl Jöreskog; Scientific Software International: Lincolnwood, IL, USA, 2001; pp. 139-168.

55. Kline, R.B. Methodology in the Social Sciences. In Principles and Practice of Structural Equation Modeling; Kline, R.B., Ed.; Guilford Press: New York, NY, USA, 2005.

56. Schreiber, J.B.; Stage, F.K.; King, J.; Nora, A.; Barlow, E.A. Reporting structural equation modeling and confirmatory factor analysis results: A review. J. Educ. Res. 2006, 99, 323-338. [CrossRef]

57. Raykov, T.; Marcoulides, G.A. A First Course in Structural Equation Modeling; Erlbaum: Mahwah, NJ, USA, $2000 ;$ ISBN 0805835687.

58. Wolf, E.J.; Harrington, K.M.; Clark, S.L.; Miller, M.W. Sample Size Requirements for Structural Equation Models: An Evaluation of Power, Bias, and Solution Propriety. Educ. Psychol. Meas. 2013, 73, 913-934. [CrossRef] [PubMed]

59. Byrne, B.M. Structural Equation Modeling with AMOS: Basic Concepts, Applications, and Programming; Routledge: New York, NY, USA, 2016; ISBN 9781315757421.

60. Byrne, B.M. Structural Equation Modeling with Mplus: Basic Concepts, Applications, and Programming; Routledge: New York, NY, USA, 2012; ISBN 9781848728394.

61. Schmitt, T.A. Current methodological considerations in exploratory and confirmatory factor analysis. J. Psychoeduc. Assess. 2011, 29, 304-321. [CrossRef]

62. Taber, K.S. The Use of Cronbach's Alpha When Developing and Reporting Research Instruments in Science Education. Res. Sci. Educ. 2018, 48, 1273-1296. [CrossRef]

63. Field, A. Discovering Statistics Using SPSS: (and Sex and Drugs and Rock "N" Roll), 3rd ed.; SAGE Publications: Los Angeles, CA, USA, 2009; ISBN 9781847879066.

64. Hooper, D.; Coughlan, J.; Mullen, M.R. Structural Equation Modelling: Guidelines for Determining Model Fit. Electron. J. Bus. Res. Methods 2008, 6, 53-60.

65. Coale, A.J. How a Population Ages or Grows Younger. In Population Growth; Routledge: New York, NY, USA, 2017; pp. 47-58.

66. Revelle, W. How To: Use the Psych Package for Factor Analysis and Data Reduction; Northwestern University, Department of Psychology: Evanston, IL, USA, 2020.

67. Javid, M.A.; Okamura, T.; Nakamura, F.; Tanaka, S.; Wang, R. Public Perceptions to Travel Demand Management Measures in Lahore, Pakistan: Analysis and Implications. Proc. Pakistan Acad. Sci. 2014, 51, 17-29. 